\title{
Fall Meeting Symposia Summaries
}

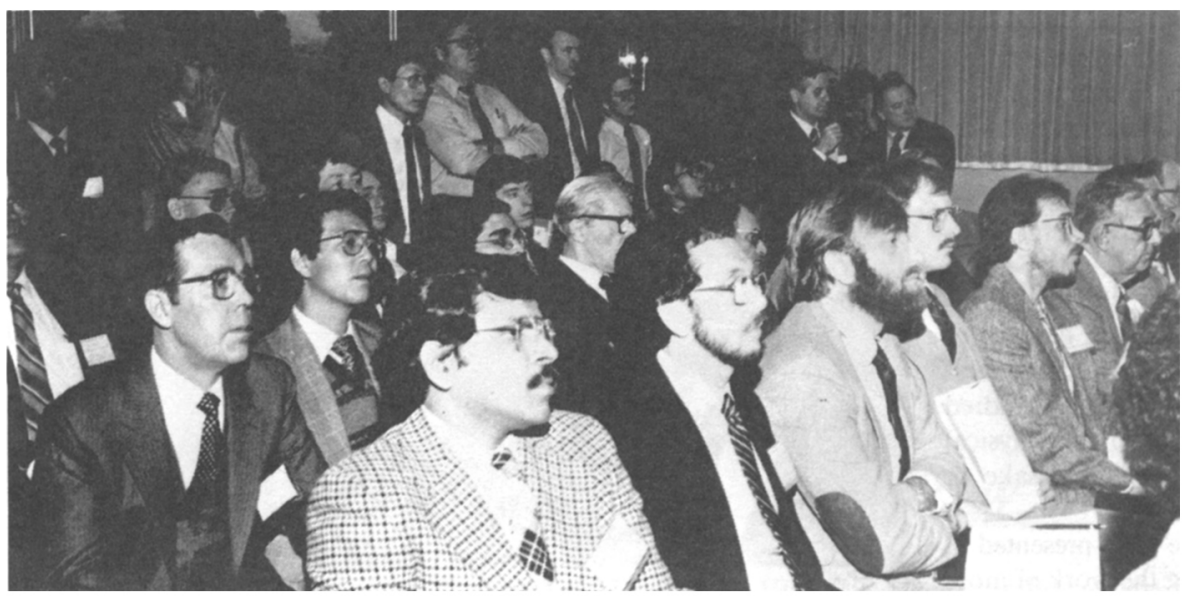

\section{ENERGY BEAM-SOLID INTERACTIONS AND TRANSIENT THERMAL PROCESSING (Symposium $A$ )}

\section{K. Biegelson, G. A. Rozgonyi, and C. V. Shank}

The Symposium on Energy Beam-Solid Interactions and Transient Thermal Processing, held November 26-30, focused on three main areas: ultrafast electronic and structural processes in highly excited materials (principally silicon); defects, impurity effects, and structural evolution during rapid thermal annealing (millisecond to ten second time scale); and crystal growth of semiconductors over amorphous insulators (SOI).

The ultrafast processes in highly excited materials sessions covered a number of topics in the area of highly excited materials studied with short pulse diagnostics. G. Mourou reported recent results using a novel picosecond electron pulse to study a laser-induced phase transition in aluminum by means of time-resolved diffraction. $H$. Kurz reported the latest results on the influence of phonons in picosecond photon-solid interactions. J. Bok discussed his recent work on the evolution of the reflectivity of silicon irradiated with femtosecond optical pulses, and a number of other papers explored the area of time-resolved melting and phase transitions.

The rapid thermal processing segment consisted of 32 oral and poster papers devoted to solid phase transient annealing phenomena. A fundamental issue highlighted during these sessions was addressed by invited speaker T. Siedel of AT\&T Bell Labs, who discussed the relation between substrate doping, the dispersion of the absorption coefficient, and the accurate and meaningful measurement of surface temperature. Enhanced dopant diffusion, residual damage, the influence of point defects; and the options for modeling dopant profiles, were covered in an invited talk by Richard Fair of MCNC. Problems unique to compound semiconductors were reviewed by Jim Williams of RMIT, while John Fan and Bor Tsaur of MIT/Lincoln Labs covered overall implications for device processing.

This year Symposia C and A coordinated their papers on RTA and diffusion during two joint sessions. The broad-based technological interest in exploring new options for implantation annealing, controlled diffusion, ultrathin oxides and sulfides, as well as combinations thereof, is so strong that a full-scale symposium on transient thermal processing has been scheduled for the 1985 Fall Meeting, organized by T. Seidel, T. Sedgwick, and B. Tsaur.

In the area of SOI, the materials issue of interface stability and the origin and control of low angle grain boundaries were emphasized. Advances in lateral epitaxial overgrowth techniques were presented in liquid and solid phase crystallization. Two excellent review papers were given which outlined device applications for SOI technologies. Finally, Walter Brown courageously presented an excellent review of the symposium and pointed to areas of future development.

Symposium Support: Army Research Office, Electronics Division; Office of Naval Research, Air Force Office of Scientific Research.

Proceedings: Energy Beam Solid-Interaction and Transient Thermal Processing. edited by D. K. Biegelson, G. A. Rozgonyi, and C. V. Shank. Member Price \$36; List Price (until April 1): $\$ 45$ (U.S.) and \$52 (foreign).
LASER CHEMICAL PROCESSING OF SEMICONDUCTOR DEVICES (Symposium B)

T. F. Deutsch, R. M. Osgood, Jr. and F. A. Houle

Symposium B, held November 27-28, was one of the major meetings of the year for those interested in both science and applications of laser chemical modification of surfaces. This is a rather new field which is currently undergoing rapid evolution. As remarked by Dan Ehrlich during his plenary lecture, two principal themes are apparent in current work. First, efforts are being made to determine just what is novel and unique about laser-surface chemistry as opposed to, for example, simple laser modification of physical properties, or plasma processing. Second, once unique aspects have been identified, a major challenge is to learn how to apply them to current and future technologies. The scope of the symposium reflected the breadth of this rapidly expanding field. Individual sessions were held on semiconductor film growth, process diagnostics, metal film deposition, fundamental processes, photochemical etching and dielectric formation. In addition, a plenary session of review papers portrayed the present level of fundamental understanding of basic phenomena, and summarized in general the status of the field.

The symposium consisted of four plenary papers, nine invited talks, and 35 contributed papers (poster, oral and late news poster). The papers could also be categorized on the basis of their primary emphasis: very applied (engineering, advanced technology), mixed applied-fundamental (applications driven, but supported by some scientific activities), and very basic (scientific studies of the type normally done in universities).

Surprisingly, the three groups were found to be roughly equal in size. Sixteen of the papers were very applied, 14 mixed, and 14 very basic. This indicates that overall there is indeed an integrated approach to studies in this field, which has not always been the case. In the past, the dominant interest has been in applications, and rather few detailed scientific studies were reported. This was not a deliberate omission, but rather reflected the fact that surface photochemistry is a very new area, and that the data base and diverse techniques required to perform detailed experiments simply were not there. It is to be expected that there will be a continued evolution in the future toward more sophistication in understanding of key phenomena and development of applications.

A number of new results were reported at this meeting, some examples of which are mentioned here. There has been a lot of progress in the area of photodeposition. Several reports were presented on epitaxial growth of crystalline compound semiconductors, notably InP and HgCdTe. Noble metals such as $\mathrm{Cu}, \mathrm{Au}$, and $\mathrm{Pt}$, which had not been deposited prior to this year, were the subject of seven papers. The first report was made of a working, laser-deposited catalyst for polymer formation. Laser diagnostics of gas phase and surface phenomena also showed new activity. Studies were presented on development of, for example, analytical methods for detecting extremely small impurity concentrations in solid materials. Identification of key processing aspects of applications of laser photodeposition and etching has enjoyed new attention. Parameters affecting metal resistivities were described, 
as well as specific studies of interface defect densities for laser processed as opposed to plasma or wet chemical processed semiconductor devices.

In additon to these specific studies, some new themes were very much in evidence this year. A new emphasis on materials characterization by, for example, x-ray photoemission, Auger spectroscopy, Rutherford backscattering, and transmission electron microscopy was evident. In the past, descriptions of laser processing results were frequently limited to rates and scanning electron micrographs.

Another new idea that inspired several studies is that photogenerated charge carriers cannot only affect etching rates, but also can be manipulated to achieve specific chemical reactions. This evolution is remarkable considering that the fact that charge carriers could be important in laser-gassurface systems was only just demonstrated in 1983 .

As indicated by the heavy attendance at all sessions, this Symposium has very broad appeal. The mix of science and technology permits significant cross-fertilization of ideas between groups having different goals. Consequently, the field covered by the symposium continues to change rapidly and appears to be growing in a number of new directions.

Principal Symposium Support: Air Force Office of Scientific Research, Army Research Office, Office of Naval Research.

Supplemental Support: IBM Corporation, Lambda Physik, LASERTECHNICS.

Extended Abstracts: Laser Chemical Processing of Semiconductor Devices, edited by F. A. Houle, T. F. Deutsch, and R. M. Osgood, Jr. Member Price: \$5; List Price $\$ 7$.

\section{IMPURITY DIFFUSION AND GETTERING IN SEMICONDUCTORS (Symposium C)}

\section{R. B. Fair, C. W. Pearce, and J. Washburn}

Topics discussed at this symposium, held November 27-30, included impurity behavior, diffusion, and oxygen in silicon. Precipitation and complexing of metals in silicon as well as their electrical activity, solubility, and diffusivity were discussed. Analytical techniques for impurity mapping or detection were compared, and the importance of using several analytical tools were stressed. Gettering processes were also discussed. Evidence was presented that shows gettering of $\mathrm{Ni}, \mathrm{Au}$, and $\mathrm{Fe}$ to be governed by the availability of self interstitials in silicon. Methods of gettering metallic impurities were presented such as deposited films, implantation damage, and epitaxial misfit dislocations.

The role of point defects in silicon and their influence on diffusion, extrinsic defect growth, and gettering were presented in two sessions. Questions addressed were the relative contributions of vacancies and self-interstitials to impurity diffusion as well as their own diffusivities and concentrations. New data regarding the strain and pressure dependence of diffusion were presented, but no definitive conclusions can be made regarding the mechanisms involved.

Two sessions were also devoted to oxygen in silicon. Mechanisms regarding intrinsic gettering, denuded zone formation, nucleation, and growth of oxygen precipitates were discussed.

Principal Symposium Support: Army Research Office, Office of Naval Research, AT\&T Technologies.

Supplemental Support: Microelectronics Center of North Carolina

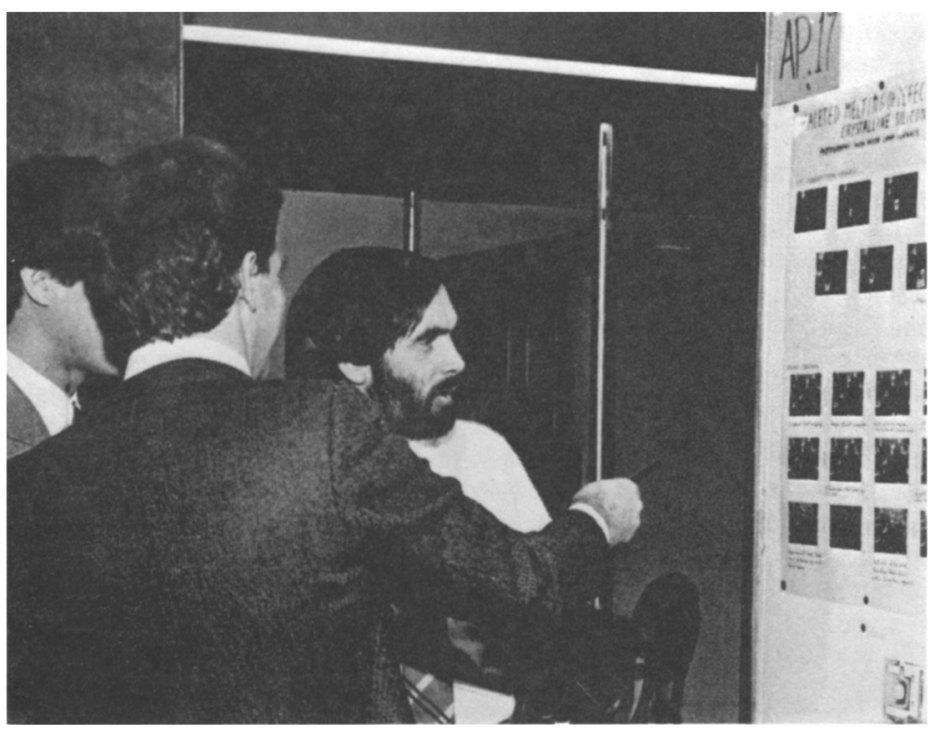

Proceedings: Impurity Diffusion and Gettering in Semiconductors, edited R. B. Fair, C. W. Pearce and J. Washburn. Member Price: \$25; List Price (until April 1): \$31 (U.S.) and $\$ 39$ (foreign).

\section{LAYERED STRUCTURES, EPITAXY AND INTERFACES (Symposium D)}

\section{J. Murray Gibson and L. Ralph Dawson}

This symposium was a highly successful innovation which brought together materials scientists involved in the growth, characterization, and unique physical properties of layered structures and epitaxial thin films. Its truly interdisciplinary nature was very consistent with the goals of the Materials Research Society. The symposium was led off by Horst Stormer (AT\&T Bell Labs), who described some of the exciting advances in physics which have been possible through the best semiconductor materials technology. It appears that even the radius of an electron may be measurable from semiconductor quantum well structures! Bob Burnham (Xerox) described the growth of such structures by MOCVD. The intriguing topic of amorphous semiconductor superlattices was introduced by Ben Abeles of Exxon, ably followed by one of the MRS Student Award winners, James Kakalios of the University of Chicago.

Don Pashley gave a keynote review of research in epitaxy, which had in the past concentrated on metals but whose results are appropriate to the more practically important field of semiconductors. A lively session on the expitaxy of insulators on silicon was led off by Julia Phillips (AT\&T Bell Labs) and included exciting electrical results from another Student A ward winner, Trey Smith of Brown University, and structural results from several groups studying the alkalline-earth fluorides on silicon.

Gordon Osbourn (Sandia), Wyn Laidig (North Carolina), and John Bean (AT\&T Bell Labs) were the properties, characterization and structure trinity of a stimulating session on strained-layer superlattices. The stability of these structures was addressed in the following session by Franz Spaepen (Harvard University), with provocative contributions from Robin Farrow (Westinghouse) and Joe Greene (Illinois) on epitaxy as a means of stabilizing metastable structures.

Ray Tung (AT\&T Bell Labs) introduced a session on the new field of single-crystal metals on silicon in which later Jerry Woodall (IBM) talked about metal/III-V interfaces. Bob Sinclair gave a colorful presentation on high-resolution electron microscopy of interfaces. Metallic superlattices, which can have unusual superconducting and elastic properties, were the subject of an interesting session which featured Dennis McWhan (AT\&T Bell Labs) who described $x$-ray studies of superlattices. Finally the importance of Schottky barrier contacts was demonstrated by the exceptionally large attendance commanded by King Tu of IBM, on Friday afternoon. Principal Symposium Support: U.S. Army Research Office, U.S. Office of Naval Research.

Proceedings: Layered Structures, Epitaxy and Interfaces, edited by J. M. Gibson and L. R. Dawson. Member Price: \$36; List Price (until April 1): \$45 (U.S.) and \$52 (foreign).

\section{HETEROGENEOUS CATALYSIS BY SOLIDS: BULK PROPERTIES, AND DEFECTS (Symposium E)}

\section{R. R. Chianelli, P. Ross, and G. A. Somorjai}

This Symposium, held November 26-30, followed an interdisciplinary program in the spirit of the MRS. Heterogeneous catalysis by solids is a complex phenomenon. Reacting molecules are adsorbed on "active sites" on the surface of a solid. The properties of the active sites are determined by the

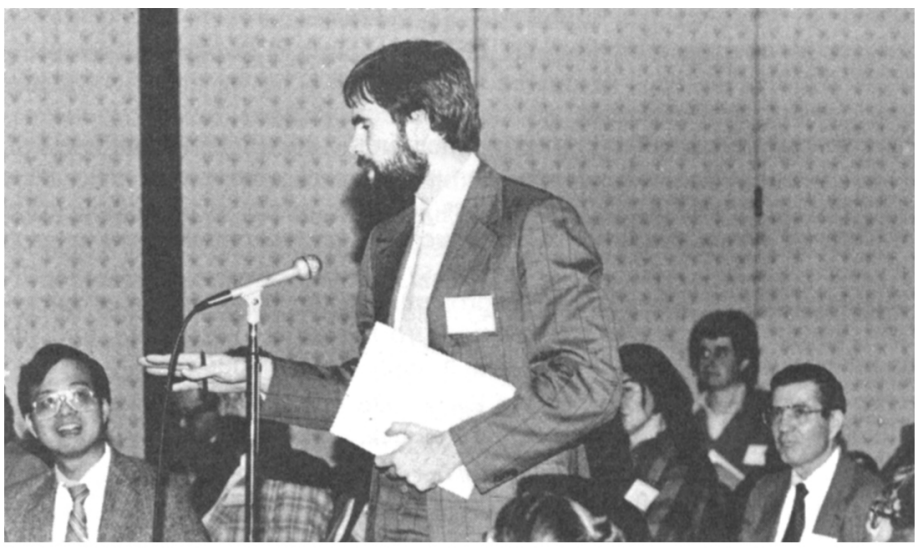


properties of the solids on which they are supported. To understand and control this industrially crucial phenomenon requires the input of many separate disciplines which were represented in the symposium.

The opening day of the symposium covered over 50 years of research in catalysis by noble metals. Prof. V. Haensel formerly of UPO and now at University of Massachusetts described how noble metal catalysts came into commercial use in petroleum reforming replacing the much cheaper catalysts of the day. J. H. Sinfelt, the 1984 Perkins medal winner, described his pioneering work at Exxon Research and Engineering $\mathrm{Co}$. in catalysis by noble metals. His colleagues at Exxon, C. Meitzner and K. S. Liang, described the latest in catalyst research. Dr. Liang's technique "differential analomous scattering" promises to give much more quantitative information about catalyst structure than the widely used EXAFS techniques. The opening session was followed by sessions on theoretical approaches to catalysis by solids, the relation between bulk and surface properties, small particles in catalysis, and special sessions on sulfide, oxide and novel catalytic materials. An example of the interdisciplinary nature of the symposium was offered by Dr.P. Pfeifer of the U. Bielefeld, West Germany on fractal analysis as applied to heterogeneous catalysts. Dr. Pfeifer also participated in the symposium on Fractal Aspects of Materials.

Principal Symposium Support: Exxon Research and Engineering Company, Schlumberger-Doll Research.

\section{PLASMA SYNTHESIS AND ETCHING OF ELECTRONIC MATERIALS (Symposium F)}

\section{R. P. H. Chang and B. Abeles}

This symposium held November 27-30, was organized to maximize the technical information exchange among scientists and engineers who are involved in the research and development of electronic materials in the various plasma media. A total of seven sessions with one late news session was included in the program. Topics varied from basic mechanisms of material synthesis and etching to applications in micro-fabrications of electronic materials. Plasma physics and chemistry play important roles in determining materials formation.

A session on plasma diagnostics was thus included. A total of about 70 talks were given with a lot of discussions after most of the talks. The Symposium Speakers' banquet was held on November 29 at the Joyce Chen Restaurant. A crowd of about 70 people enjoyed a nine-course dinner with Peking duck.

Symposium Support: Office of Naval Research, U.S. Army Research Office, Applied Materials, ARCO-Solar, Branson IPC, Drytek, DynaVac, Eaton, Energy Conversion Devices, GCA Corporation, Lam Research, LFE, Materials Research Corporation, Perkin-Elmer, Plasma-Therm, Solarex, Technics, Tegal.

Proceedings: Plasma Synthesis and Etching of Electronic Materials, edited by R. P. H. Chang and B. Abeles. Member Price: \$30; List Price (until April 1): \$38 (U.S.) and \$48 (foreign).

\section{HIGH-TEMPERATURE ORDERED INTERMETALLIC ALLOYS (Symposium G)}

\section{C. Koch, C. T. Liu, and N. S. Stoloff}

Symposium G, held November 26-28, included discussions of the physical metallurgy and mechanical behavior of ordered intermetallic alloys which have the potential for use as new structural materials. High interest in these topics required a move to a larger room during the first sessions. Invited review papers and contributed research abstracts were presented in the areas of theory of alloy ordering, microstructural features and phase transformation, mechanical behavior, alloy design, and physical properties. A keynote address by Prof. Norman Stoloff gave a good overview of the field as well as suggestions of areas which require further research. The potential for using ordered alloys has been hampered by the brittle behavior and low fracture toughness of these materials.

In recent years significant improvement in the ductility and toughness of, first, titanium aluminides, then iron and nickel aluminides have been achieved by metallurgical techniques such as processing control, grain refinement, and microalloying. These successes have stimulated new interest in these materials and this three-day symposium gave a forum for the discussion of the new exciting improvements, the mechanisms of microstructural-property relationships unique to the ordered structure, and the many gaps in our understanding which require more study.

Symposium Support: Department of Energy, Division of Energy Conversion and Utilization Technologies, Office of Naval Research.

Proceedings: High-Temperature Ordered Intermetallic Alloys, edited by C. C. Koch, C. T. Liu, and N. S. Stoloff. Member Price: \$30; List Price (until April 1): \$38 (U.S.) and $\$ 48$ (foreign).

\section{HYDROGEN IN METALS (Symposium H)}

\section{W. D. Wilson, M.-R. Louthan, Jr., and H. Birnbaum}

The hydrogen in metals symposium was highlighted by excellent speakers, spirited discussion and, perhaps, the lack of agreement. Thermodynamic calculations and experimental evidence were presented to show that both external stresses and lattice defects influence the solubility, diffusivity, and permeability of hydrogen in a wide variety of metals and alloys. Dislocations, grain boundaries, vacancy clusters, impurity atoms, second phase particles, and even coherent twin boundaries were proposed as trap sites. Some suggested that such traps were quite deep in austenitic steels while other investigators proposed limited trapping at these same defects. Some researchers reported that hydrogen interaction with dislocations enhances dislocation mobility in several alloys; others suggested that these same interactions retarded dislocation motion.

Hydrogen embrittlement processes in metals and alloys were shown to exist from temperatures as low as $77 K$ to well above room temperature and at strain rates from zero (sustained load crack growth) to those characteristic of an impact test. Hydrogen adsorbtion was proposed to modify the response of a crack to an applied stress, and hydrogen absorption was proposed to lower the strength of various metallurgical interfaces. Ion channeling, EXAFS, ultrasonic attenuation, magnetic measurements, atom probe studies, and microbeam analysis were shown to be effective experimental techniques for locating hydrogen atoms. Thermodynamics-statistical mechanics, the effective medium theory, and the embedded atom method were shown to be powerful tools for calculating hydrogen-induced effects in metals.

In spite of the disagreement and the firm "tongue-in-cheek" commitment to the theme that "each to his own work will refer, ignoring those that don't concur," the symposium closed with improved friendships and communication among the attendees.

Principal Symposium Support: Army Research Office.

\section{GRAPHITE INTERCALATION COMPOUNDS (Symposium I)}

\section{P. C. Eklund, M. S. Dresselhaus, and G. Dresselhaus}

The MRS Symposium of Graphite Intercalation Compounds (cosponsored as a Topical Conference by the APS) was an intensive three-day report of the state-of-the-art on these important layered materials. The attendance was international with papers from the United States, Japan, France, Belgium, Canada, Germany, and Israel. The pace of the symposium

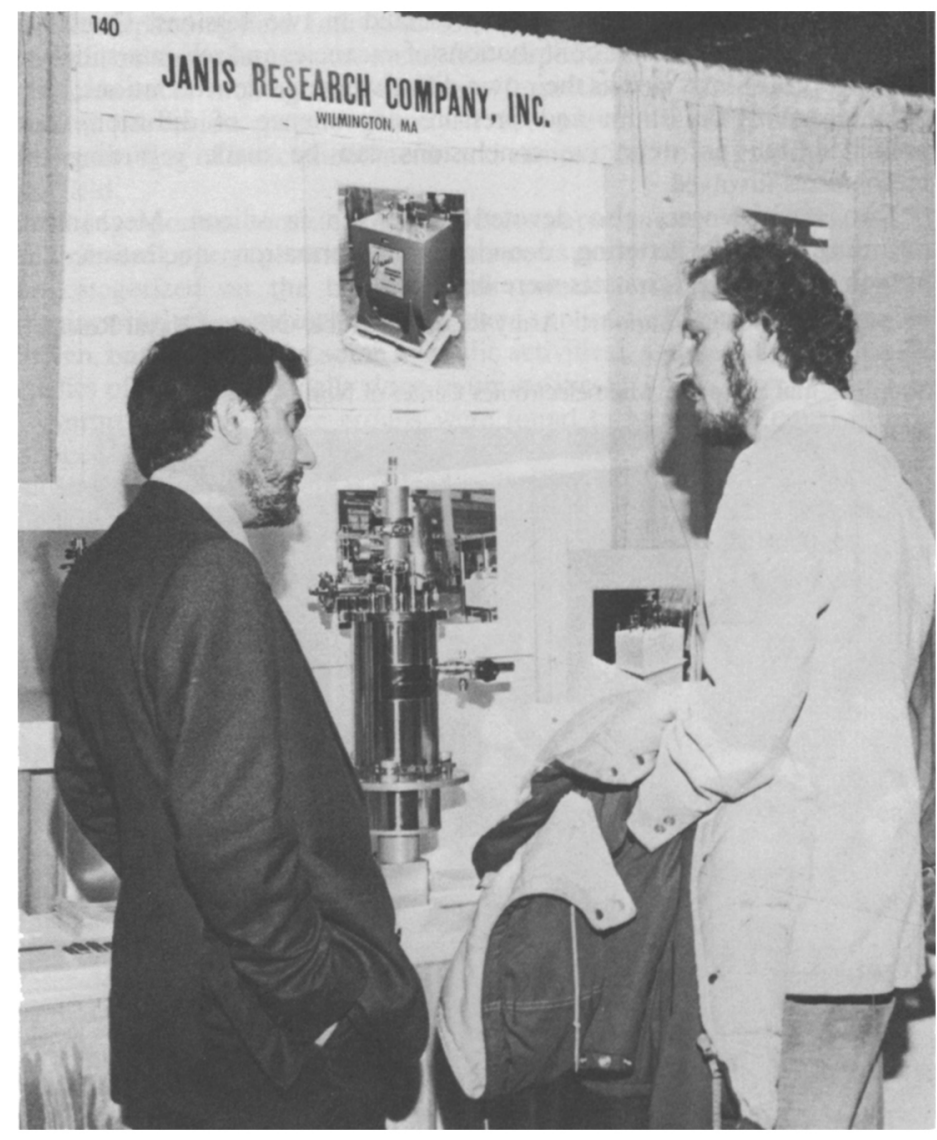


was very intense, but the attendees insisted on an extra one-hour free-for-all discussion period during the lunch break each day. Particularly notable advances were made in the areas of structural determinations, intercalation mechanisms, magnetic properties, ternary intercalation compounds, as well as new advances in graphite fiber research.

This was the second symposium on this subject at an MRS Fall Meeting. The increase in papers by about $50 \%$ and the enthusiastic response suggests that this community would welcome a third symposium on this topic in about two years.

Principal Symposium Support: NASA Lewis Research Center, Army Research Office.

Industrial Support: General Motors Research Laboratory, Union Carbide Corporation, Parma Technical Center.

Extended Abstracts: Graphite Intercalation Compounds, edited by P. C. Eklund, M S. Dresselhaus, and G. Dresselhaus. Member Price: \$5; List Price \$7.

\section{ELECTRONIC PACKAGING MATERIALS SCIENCE (Symposium J)}

\section{E. A. Giess, K.-N. Tu, and D. R. Uhlmann}

The new symposium on Electronic Packaging Materials Science, held November 27-29, addressed the multidisciplinary materials sciences necessary to support improvements in the complex packages used to carry and interconnect electronic devices. Topics included in the symposium were: materials processing principles; composites and interfaces of ceramics, metals and polymers; fracture mechanics; interface failure and fatigue; interdiffusion and reactions in mixed systems; and interface characterization techniques.

Symposium chairmen E. A. Geiss (IBM), K.-N. Tu (IBM), and D. R. Uhlmann (MIT) organized 50 presentations into seven sessions, including 19 invited papers. D. Eastman, director of IBM's Advanced Packaging Technology Laboratory, initiated the symposium with an overview of the state of the art before a standing-room-only crowd. Semiconductor chip technology has progressed to the point where, according to Eastman, improvements in system performance will have to be achieved in packaging. The complexity and possibilities in mounting and interconnecting devices offers very many opportunities for innovation.

The remaining sessions provided balanced coverage of the major topics of the symposium and experienced a steady level of attendance. The multidisciplinary breadth of this subject made the Materials Research Society a natural forum for this symposium.

Principal Symposium Support: Alberox Corporation, General Electric Research \& Development Center, International Business Machines Corporation, and Stauffer Chemical Company.

Proceedings: Electronic Packaging Materials Science, edited E. A. Giess, K.-N. Tu, and D. R. Uhlmann. Member Price \$25; List Prices (until April 1):\$31 (U.S.) and \$39 (foreign).

\section{ADVANCED PHOTON AND PARTICLE TECHNIQUES FOR THE CHARACTERIZATION OF DEFECTS IN SOLIDS (Symposium K)}

\section{J. B. Roberto, R. W. Carpenter, and M. C. Wittels}

Sixty papers were given during this three-day symposium held November 27-29. The symposium covered recent advances in the applications of neutron, $x$-ray, and electron scattering to solids containing a wide variety of defects. Emphasis in $\mathrm{x}$-ray and neutron discussions was on interpretation of results and extensions of the theory for elastic diffuse scattering. Combined use of neutron and transmission microscopy to study voids in metals was particularly interesting. Electron scattering papers dealt with the new generation of HREM fixed beam instruments, their expected resolution limits, and the extended range of interpretable defect images in small unit cell crystals that these instruments will carry into the range of possible quantitative research.

Several papers on analytical electron microscopy generated profound interest. In particular, it was shown by Dr. Paul Okamoto, et al., that lattice defects introduced in the irradiated volume of a crystalline foil being examined by energy dispersive $x$-ray micro-analysis will cause easily measurable changes in composition of the irradiated volume. The effect is pronounced and depends on point defect concentration gradients in the irradiated volume. This observation has very important consequences for high voltage AEM, which is now clearly a mixed blessing, and is going to be intensely examined in many laboratories in the near future.

The authors distinguished themselves in providing excellent coverage of the field from introduction to current research. The symposium was well attended, and the proceedings will be unusually useful in defining the state of knowledge in the field for the next several years.
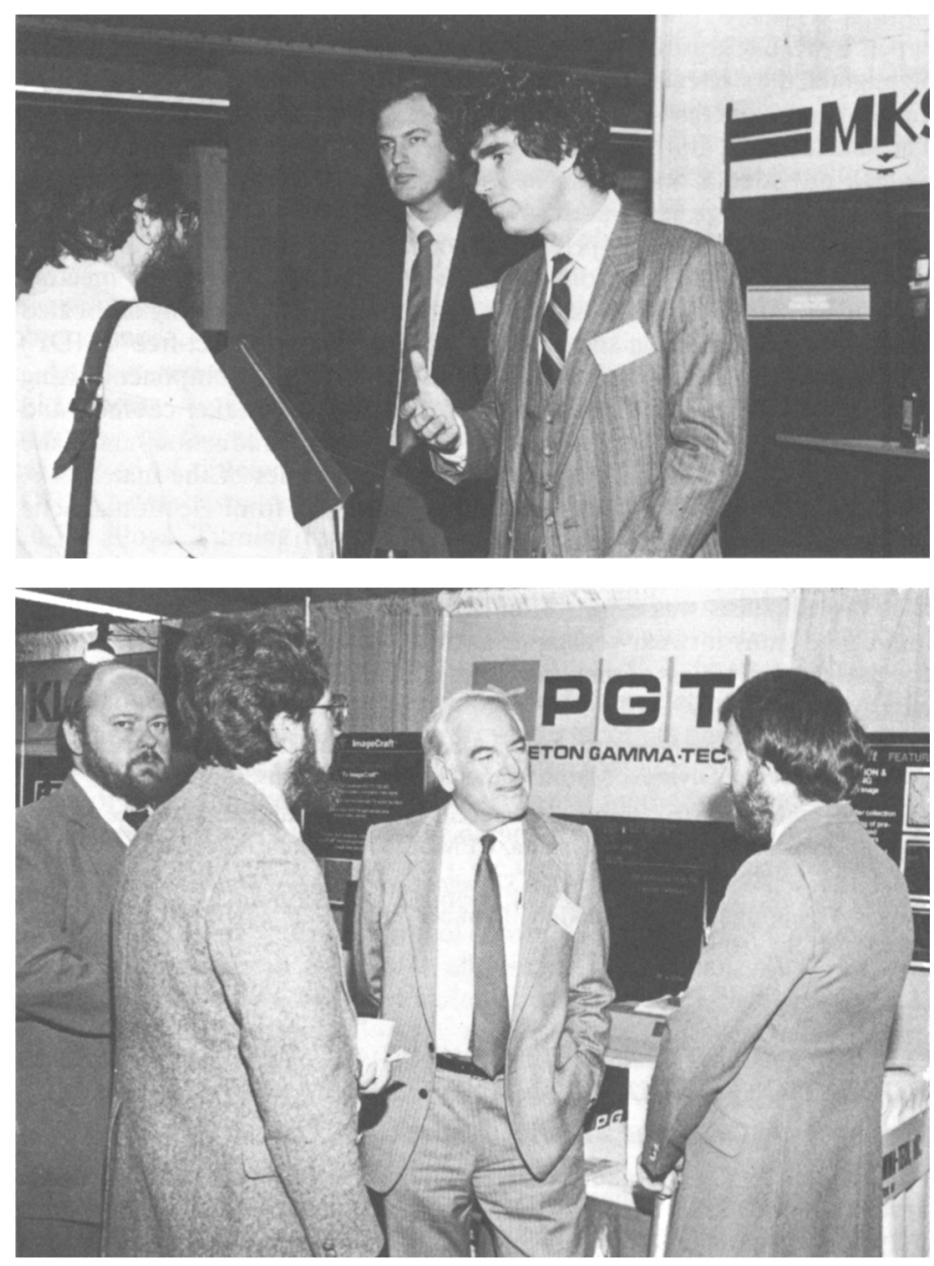

Principal Symposium Support: Division of Materials Sciences, Office of Basic Energy Sciences, U. S. Department of Energy.

Industrial Support: Philips Electronic Instruments, Inc., JEOL USA, Inc.

Proceedings: Advanced Photon and Particle Techniques for the Characterization of Defects in Solids, edited by J. B. Roberto, R. W. Carpenter, and M. C. Wittels. Member Price: \$30; List Price (until April 1): \$38 (U.S.) and \$48 (foreign).

\section{POTENTIAL FOR VERY HIGH STRENGTH CEMENT-BASED COMPOSITES (Symposium L)}

\section{J. Francis Young and Sidney Mindess}

Portland cement and other inorganic cements have been traditionally used in the less demanding applications (from a materials point of view) of civil engineering. However, even as civil engineers and cement scientists have been steadily developing high-performance concretes and mortars, there has emerged completely new and parallel developments that are opening up new opportunities for cement-based systems in applications hitherto occupied by plastics or metals. This two-day symposium, held November $27-28$, was designed to chart the progress of both lines of development, and attracted a large attendance of about 90 persons, including a large contingent from Europe.

The first two sessions concentrated on fundamental studies on the properties of cement-based systems in general. Papers by $M$. Regourd (France), S. Mindess (Canada), and J. F. Young (United States) reviewed factors that control strength and highlighted recent developments. Regourd concentrated on the microstructure of cement paste, Mindess on the mesoand macrostructure of concrete, and Young on porosity-property relationships. Several papers gave considerable insights into the strengthening mechanisms of the newer materials, and a lively exchange of views on the applicability of fracture mechanics to these systems resulted. The relationship between pores, Griffiths flaws, and strength is one issue that has a considerable number of diverging viewpoints, which should provide impetus for future research.

The third session concentrated on the more mundane, but equally important and interesting, aspects of production and application. Review 
papers by R. L. Carasquillo (United States) and W. T. Hester (United States) highlighted the strategies for attaining successful and economic production of high-strength concrete, and new approaches to the problem were presented. The final session, introduced with an overview by $\mathbf{S}$. Diamond (United States), provided a fascinating insight into the new applications that are beginning to emerge. High-performance molds for the aircraft and aerospace industries have been developed from specially designed particulate systems and are surpassing the more traditional aluminum molds in meeting demanding specifications. Less exotic automobile parts are being fabricated in cement-based injection and press molds. The "macro-defect-free" (MDF) cements are also being used to manufacture a variety of components using forming techniques that are already in common use. Speaker cabinets and turntables for stereo systems are in commercial production and take advantage of the excellent acoustic damping properties of the material. A potential was also seen for the material as shielding from electromagnetic interference and from projectiles (i.e., armor).

Several new applications were also described in the civil engineering field. Here the emphasis was as much on high performance as on high strength. Impressive gains in wear resistance and impermeability were documented and presage a new class of materials to use in the rehabilitation of the nation's infrastructure.

Principal Symposium Support: National Science Foundation, Civil and Environmental Engineering Division, Martin Marietta Energy Systems, Inc.

Supplemental Support: Imperial Chemical Industries Ltd., W. R. Grace \& Co., Elkem Chemicals Inc., Martin Marietta, CEMCOM Research Associates.

Proceedings: Potential for Very High Strength Cement-Based Materials, edited by J. Francis Young and Sidney Mindess. Member Price: $\$ 25$; List Price (until April 1): $\$ 31$ (U.S.) and $\$ 39$ (foreign).

\section{COAL COMBUSTION AND CONVERSION WASTES: CHARAC- TERIZATION, UTILIZATION AND DISPOSAL (Symposium M)}

\section{Gregory J. McCarthy and Robert J. Lauf}

Vast quantities of inorganic materials are produced when coal is burned or gasified. Some of this by-product, the fly ash produced from combustion of pulverized coal, is used for cement replacement in concrete and other civil engineering practices. However, the bulk of the material is not currently used and is treated as a waste to be stored in temporary holding ponds or buried in landfills or reclaimed strip mines. In Symposium M, 22 papers presented to an audience averaging 40 persons dealt with the contributions that materials science and engineering can make in finding and optimizing uses for coal's inorganic by-products as well as providing the scientific basis for their safe disposal.

The state of the art in the characterization of fly ash and fly ash-containing mortars and concrete was the subject of the keynote paper presented by Prof. Della M. Roy of the Pennsylvania State University. X-ray diffraction, scanning electron microscopy, and thermal analysis are most often employed in characterizing these materials and their reactions. These techniques were highlighted in many of the papers that followed along with others ranging from time-honored petrographic microscopy to the first results to be obtained from the new microfocus laser Raman instruments. Notably lacking at this time is the transmission microscopy work necessary to characterize the sub-micrometer crystalline and noncrystalline phases in the ash and the materials incorporating ash. A second inadequacy in our understanding of these materials noted by speakers and participants was documentation of coal's inorganic constituents and its preparation, combustion, and ash collection. It was widely appreciated that these parameters have important effects on the nature and properties of the inorganic by-products.

The discussions following each paper and during breaks were lively, and the participants expressed their pleasure at seeing the integrated technical approach to utilization or disposal of these materials. Utilization options included the well-established replacement of some of the cement in concrete by fly ash as well as road bed stabilization and oil well cementing applications. Characterization and potential uses for the ash from the first commercial coal gasification plant in the United States were presented by scientists and engineers from the North Dakota universities.

A novel approach to disposal in a useful form was described in a paper and film by Carol Hornibrook of the New York State Energy Research and Development Authority. Scrubber waste, fly ash, and other additives were fashioned into blocks and used to build an artificial reef in Long Island Sound that is now heavily populated by aquatic species. Processes that employ coal ash as a source of aluminum were discussed by workers from the Oak Ridge National Laboratory. While not economical at present, coal ash could

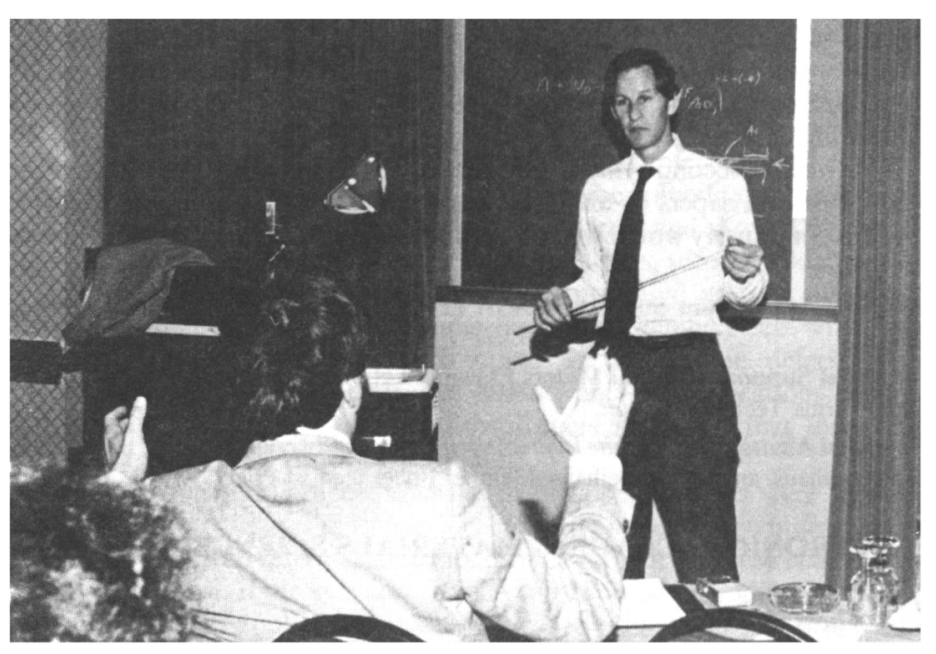

become a principal source of aluminum in case of any future bauxite shortage.

The symposium will be held again at the 1985 Fall Meeting under the title "Fly Ash and Coal Conversion By-Products: Characterization, Utilization and Disposal." The participants agreed that this symposium was unique in its approach and technical strengths and that the MRS was an appropriate home. The organizers look forward to substantial growth in the number of papers, in participation by industry and government agencies, and in international representation at the 1985 Symposium.

Principal Symposium Support: Tennessee Valley Authority

Proceedings: Coal Combustion and Conversion Wastes: Characterization, Utilization and Disposal, edited by Gregory J. McCarthy and Robert J. Lauf. Member Price: \$20; List Price (until April 1): \$25 (U.S.) and \$31 (foreign).

\section{SCIENTIFIC BASIS FOR NUCLEAR WASTE MANAGEMENT (Symposium N)}

\section{M. Jantzen, J. A. Stone, and R. C. Ewing}

The 1984 symposium was the eighth in a series of Materials Research Society International Symposia devoted to the scientific aspects of nuclear waste management. The symposium focused on the mechanisms of waste form leaching, the materials aspects of corrosion of waste package components including the waste form, and interactions of these components in the near-field repository environment. The technical program also included sessions on materials performance in repository environments, geochemical interactions, radiation effects, natural analogs, concrete in nuclear waste management, and all aspects of processing technology.

A total of 122 papers were presented in oral and poster sessions. The keynote address discussed the fundamentals of modeling waste form performance, in particular how to extrapolate laboratory data on the durability of vitreous waste forms to geologic time scales (P.B. Macedo, Catholic University of America, Washington, DC). This theme was elaborated upon by four well-known international scientists who gave invited overview papers of performance testing of nuclear waste glass and waste package components in repository-relevant environments (M.J. Plodinec, Savannah River Laboratory, Aiken, SC); recent research in used fuel dissolution (L. H. Johnson, Whiteshell Nuclear Research Establishment, Canada); generalized rate equation for nuclear waste glass corrosion (B. Grambow, Hahn-Meitner Institute, West Germany); and a repository source term conceptual model (D.H. Alexander, Department of Energy, Germantown, MD)

A special session was devoted to activities of the Materials Characterization Center at Pacific Northwest Laboratory; this session fostered international understanding of the standardization of materials testing directly related to nuclear waste management in the United States. An evening poster session was extremely successful and addressed four major technical areas: radiation effects, leaching mechanisms, modeling, and repository near-field interactions and related investigations. Papers on radiation effects covered a variety of radiation-induced materials effects on glasses, ceramics and natural mineral analogues, as well as the effects of groundwater radiolysis on materials performance. The modeling papers in the oral and poster sessions addresed many relevant topics including kinetics and thermodynamics, transport codes and mechanisms, colloidal transport and migration, effects of radiolysis, and probabilistic analysis of human intrusion in geologic time scales. 


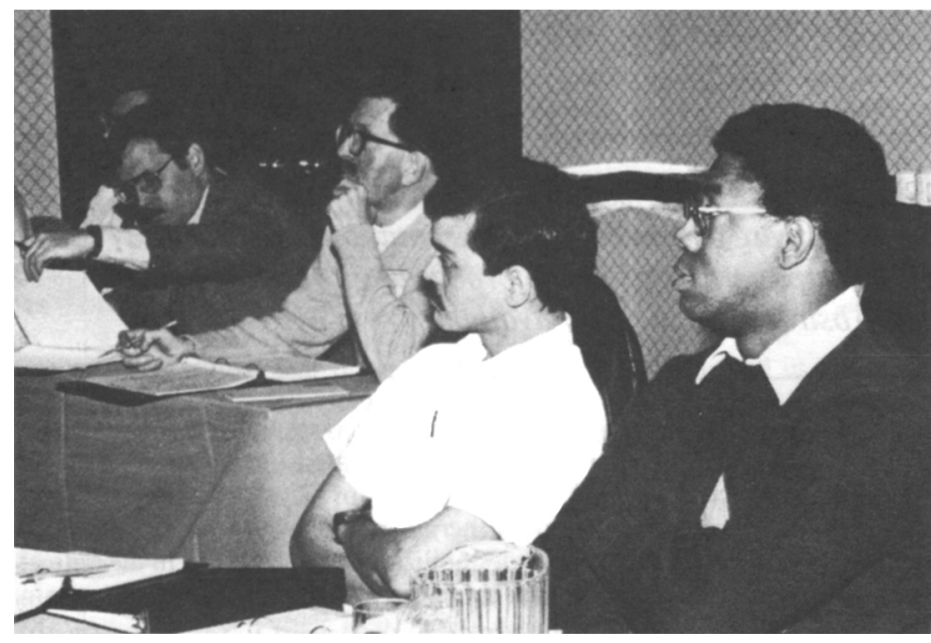

Three sessions on leaching mechanisms eloquently displayed the growing international understanding and ingenuity being used to study glass-solution interactions. Many sophisticated techniques such as SIMS, ESCA, EXAFS, FTIRS, IR, XPS, SEM/EDAX, TEM/EDAX, NRA, and TFAR are being used to characterize the glass-solution interface. Several interesting papers dealt with the reaction zones occurring at the glass-solution interface at different solution redox conditions since the redox potential in some repository environments will be reducing. Two additional sessions focused on materials performance in repository environments. The interactions and corrosion behavior of the waste form with both metallic and nonmetallic waste package components in repository environments representative of tuff, salt, basalt, and granite were reported. Many unique experimental designs are being used to obtain representative repository conditions during laboratory testing.

The symposium was well attended, with participation from 12 countries (United States, Italy, Japan,, Switzerland, Sweden, West Germany, Great Britain, Canada, Finland, Brazil, France and Belgium). International concern for an interdisciplinary approach to the scientific research related to safe disposal of nuclear waste was apparent. The theme of international collaboration prevailed and was particularly evident in the presentations given by the participants of the JSS (Japan-Switzerland-Sweden) program. International cooperation will be further strengthened with the 1985 symposium to be held in Sweden.

Principal Symposium Support: U.S. Department of Energy, U.S. Nuclear Regulatory Commission

Proceedings: Scientific Basis for Nuclear Waste Management VIII, edited by C. M. Jantzen, J. A. Stone and R. C. Ewing. Member Price: \$45; List Price (until April 1): $\$ 50$ (U.S.) and $\$ 55$ (foreign).

\section{ALLOY PHASE DIAGRAMS (Symposium $O$ )}

\section{H. Bennett, B. C. Giessen, and T. B. Massalski}

This symposium was a sequel to the symposium of the same title held two years ago and published as MRS Proceedings Volume 19 (1983) and edited by $L$. H. Bennett, et al. The previous symposium and the book based on it summarized the state of the art with sections on alloy phase stability, thermodynamic modeling, phase diagram determination and evaluation, and specialized phase diagrams. The present symposium built on this foundation by giving progress reports in such fields as calculations, data handling, novel experimental methods, and specific phase diagram studies, while breaking new ground by presenting material on surface and defect phase diagrams. Together, these symposia establish a biannual series of alloy phase diagram symposia, indicating that this field has a firm place in the spectrum of MRS symposium topics; it is expected that this series will continue in the future.

The symposium, which had international attendance, consisted of three half-day sessions and a poster session. Of the 30 papers, 14 had been invited and were presented orally while the others were presented in the form of a poster session. Papers fell into four categories: surfaces and defects; calculations and data handling (subdivided into alloy phase calculations, phase diagram calculations, data handling); experimental methods and studies (methods, phase diagram and alloy phase studies); and metastable phases and phase diagrams.
Only some of the many fine papers can be highlighted here. The series of papers on surfaces and defects drew a standing-room-only audience. The papers by M. Wortis (University of Illinois) and C. Jayaprakash (Ohio State University) focused on theoretical advances in the calculation of equilibrium crystal shapes, interfacial phase diagrams, and interfacial phase transitions; J. M. Sanchez (Columbia University) discussed calculations of surface ordering; and G. Kalonji (MIT) presented calculations of phase equilibria of solids with defects, with emphasis on two-dimensional bicrystals. In these fields, participants offered suggestions for connecting calculations and experimental observations.

Another series of presentations concerned first-principles alloy phase calculations: A. E. Carlsson (Washington University) provided a lucid overview of the appropriate interatomic potentials to be used for the calculation of different properties of transition metals, and G. M. Stocks (ORNL) demonstrated the Fermi-surface origin of concentration waves in $\mathrm{Cu}-\mathrm{Pd}$ alloys. Turning to computer studies, J. L. Murray (NBS) showed representations of data on ternaries, and B. C. Giessen (Northeastern University) presented applications of pattern recognition techniques to alloy phase classification by maps. Phase stability in $\mathrm{Cu}$ alloys was reviewed by A. P. Miodownik (University of Surrey, England), R. E. Watson (BNL) and L. H. Bennett (NBS) presented work on local atomic environments in T-X alloys, and the differentiation of correct versus incorrect phase diagrams with critical behavior was reviewed by S. M. Allen (MIT)

Major papers in the section on experimental methods treated the use of synchrotron diffraction to clarify the nature of $\mathrm{GP}$ zones in $\mathrm{Al}(\mathrm{Cu})$ alloys $(\mathrm{J}$. B. Cohen, Northwestern University), the use of NMR in crystalline systems (J. I. Budwick, University of Connecticut) and in metallic glasses (L. H. Bennett, NBS), and the application of convergent beam electron microscopy to structural studies in metastable alloys (M. J. Kaufman, NBS). Experimental studies on phase diagrams included work on the $\mathrm{Cr}-\mathrm{Ni}$ system by $\mathrm{G}$. J. Abbaschian (University of Florida); studies of new metastable alloy phases included work on phases transformed by irradiation (N. Q. Lam, ANL) and by ion implantation (D. M. Follstaedt and S. T. Picraux, Sandia National Laboratories). Although the symposium took place during the last two days of the conference, good audience participation continued throughout. Participants report the interesting professional contacts were made.

Seen together with the symposia on high-temperature ordered intermetallic alloys and on hydrogen in metals, which were also presented at the Fall Meeting, and the symposia on rapidly solidified alloys which are presented by MRS in alternating years (in rotation with the phase diagram symposia), this symposium confirmed the continued commitment of MRS to seek out frontier topics in metal alloy research for inclusion in its conference programs. Extended Abstracts: Alloy Phase Diagrams, edited by L. H. Bennett, B. C. Giessen, and T. B. Massalski. Member Price: \$5, List Price: \$7.

\section{FRACTAL ASPECTS OF MATERIALS: METAL AND CATALYST SURFACES, POWDERS AND AGGREGATES (Symposium $\boldsymbol{P}$ )}

\section{Benoit B. Mandelbrot and Dann E. Passoja}

This symposium, conducted November 26-27, was experimental for the Materials Research Society. The first invited speakers were to demonstrate to materials scientists that metal and catalyst surfaces, powders, and aggregates are examples of fractals. That is to say, while their surfaces are very far from being smooth, their structure does not vary in kind over a wide range of magnifications. In a more general sense, for diverse highly practical materials, such loose notions as "rough" and "porous" are being transformed by fractal geometry into quantitative concepts, the basic parameters being "fractal dimension."

The symposium organizers hoped to bring out further work in this field, and also hoped to alert a broad group of materials scientists to the fractal tools now at their disposal. This last goal was fulfilled, and comments during the breaks and the Tuesday night panel showed that the extent of awareness of fractals among materials scientists had been more substantial than previously thought, and continues to grow. For example, chemists are better represented than expected among those describing fully developed applications. Another specific highlight of the program was discussion of methods for evaluating fractal dimension, which have increased in number and variety. This area indicates that statistical problems will soon need to be tackled.

Symposium Support: Arco Metals Corporation, Du Pont Central Research and Development Department, EBTEC Corporation, IBM Corporation Research Division, Office of Naval Research, Perkin Elmer Corporation Physical Electronics Division, Union Carbide Corporation Linde Division.

Extended Abstracts: Fractal Aspects of Materials: Metal and Catalyst Surfaces, Powders and Aggregates, edited by Benoit B. Mandelbrot and Dann E. Passoja. Member Price: \$5; List Price \$7. 